\title{
Comportamento de sementes de feijão sob diferentes potenciais osmóticos
}

\author{
Bean seed performance under different osmotic potentials
}

\author{
Gilberto Antonio Freitas de Moraes ${ }^{1}$ Nilson Lemos de Menezes ${ }^{2}$ \\ Leandro Lourenço Pasqualli ${ }^{3}$
}

\section{RESUMO}

A hidratação é o fator externo mais importante na germinação de sementes. Para simular as condições complexas do solo, soluções com diferentes potenciais osmóticos têm sido usadas para umedecer os substratos. O objetivo deste trabalho foi avaliar os efeitos do estresse hídrico e salino sobre a germinação e o vigor de sementes de feijão. Sementes da cultivar IAPAR 44 foram colocadas a germinar em papeltoalha embebido em soluções de polietileno glicol (PEG) 6000 e cloreto de sódio ( $\mathrm{NaCl}$ nos potenciais osmóticos zero; -0,05; $-0,10 ;-0,15 ;-0,20 ;-0,25$ e-0,30MPa. O desempenho das sementes foi avaliado por meio do teste de germinação, primeira contagem da germinação, comprimento e matéria seca de plântulas. Concluiu-se que a redução do potencial osmótico, induzido por PEG 6000 ou $\mathrm{NaCl}$, reduz o vigor e, a partir de020MPa, reduz a germinação de sementes de feijão. O PEG 6000 produz efeitos adversos mais drásticos do que o $\mathrm{NaCl} \mathrm{na}$ qualidade fisiológica das sementes.

Palavras-chave: Phaseolus vulgaris L.,germinação, vigor, estresse hídrico.

\section{ABSTRACT}

Hydration is the most important external factor for seed germination. To simulate the complex soil conditions solutions with different osmotic potentials have been used to soak substrata. The objective of this paper was to evaluate the effects of hydric and saline stress to germination and strength of bean seeds. Seeds of the cultivar IAPAR were germinated in towel-paper soaked in Polyethylene glycol (PEG) 6000 and Sodium chlorine ( $\mathrm{NaCl}$ ) solutions in the zero osmotic potentials; -0.05; -0.10; -0.15; $0.20 ;-0.25$ and $0.30 \mathrm{MPa}$. Seed performance was evaluated through the germination test, first count of germination, length, and dry seedling weight. In conclusion, osmotic potential reduction, induced by PEG 6000 or $\mathrm{NaCl}$, reduces the strength and, from 0.20 to -0.30MPa, the germination of bean seeds. The PEG 6000 produces more severe and adverse effects than the $\mathrm{NaCl}$ in the physiologic quality of been seeds.

Key words: Phaseolus vulgaris L., germination, vigor, hydric stress.

\section{INTRODUÇÃO}

Dos fatores externos que interferem no processo germinativo considera-se como o mais importante a hidratação da semente, pois a água constitui a matriz onde ocorre a maioria dos processos bioquímicos e fisiológicos, que resultam na protrusão da raiz primária (BRAY, 1995). A embebição das sementes de feijão (Phaseolus vulgaris L.) foi considerada completa após seis horas, quando a matéria fresca manteve-se constante (PAULILO, 1980). Entretanto, este período pode sofrer variação, em função da qualidade da semente e do potencial osmótico do substrato (MIAN \& NAFZIGER, 1994).

O vigor das sementes de feijão é mais afetado pelo $\mathrm{NaCl}$ do que a germinação. Além do mais, a porcentagem de plântulas anormais e o diâmetro da radícula das plântulas normais aumentaram na presença do sal (PAULA et al., 1994). Da mesma forma, a

${ }^{1}$ Departamento de Biologia, Centro de Ciências Naturais e Exatas (CCNE), Universidade Federal de Santa Maria (UFSM), Santa Maria, RS, Brasil. E-mail: gafmoraes@mail.ufsm.br. Autor para correspondência.

${ }^{2}$ Departamento de Fitotecnia, Centro de Ciências Rurais (CCR), UFSM, Santa Maria, RS, Brasil.

${ }^{3}$ Aluno do Programa de Pós-graduação em Agronomia, Produção Vegetal, CCR, UFSM, Santa Maria, RS, Brasil. 
germinação e o vigor das sementes de soja são reduzidos acentuadamente com a diminuição dos potenciais osmóticos das soluções contendo $\mathrm{NaCl}$ e PEG 6000 (McDONALD et al., 1988; BRACCINI et al., 1996; MORAES \& MENEZES, 2003). O comprimento das plântulas, também, diminuiu à medida que os potenciais osmóticos, obtidos com o uso do PEG 6000 decresceram (SEONG et al., 1988; BRACCINI et al.,1998). O efeito dos potenciais osmóticos sobre as sementes e as plântulas depende da qualidade inicial da semente e do tipo de soluto utilizado quando estas são submetidas ao mesmo grau de déficit hídrico (BRAGA, et al., 1999; MORAES \& MENEZES, 2003).

Considerando que as adubações sucessivas, necessárias para o cultivo do feijoeiro, alteram o potencial de água do solo e esse, por sua vez, afeta a qualidade fisiológica das sementes, o presente trabalho teve por objetivo avaliar o efeito do estresse hídrico e salino sobre o desempenho fisiológico de sementes de feijão.

\section{MATERIAL E MÉTODOS}

O trabalho foi realizado no Laboratório Didático e de Pesquisa em Sementes (LDPS), do Departamento de Fitotecnia da Universidade Federal de Santa Maria (UFSM), durante o ano de 2003. Foram utilizadas sementes de feijão da cultivar IAPAR 44, as quais tiveram o potencial fisiológico avaliado por meio de testes de germinação e vigor, em soluções de Polietilenoglicol (PEG 6000) e Cloreto de Sódio ( $\mathrm{NaCl}$ ) nos níveis de potenciais osmóticos correspondentes a zero; - 0,05; - 0,10; - 0,15; - 0,20; - 0,25 e - 0,30 MPa. As quantidades de $\mathrm{NaCl}$ para se obterem os referidos potenciais foram calculadas a partir da equação de Van't Hoff, enquanto as de PEG 6000 foram obtidas com base em MICHEL \& KAUFMAN (1973) (Tabela 1).

O teste de germinação foi conduzido a $25^{\circ} \mathrm{C}$, utilizando quatro repetições de 50 sementes por

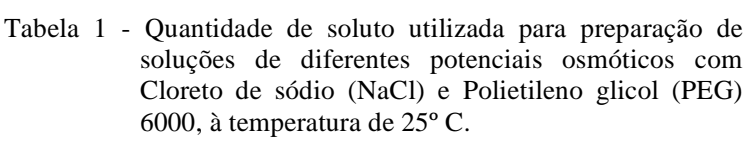

Tabela 1 - Quantidade de soluto utilizada para preparação de soluções de diferentes potenciais osmóticos com Cloreto de sódio ( $\mathrm{NaCl}$ ) e Polietileno glicol (PEG) 6000 , à temperatura de $25^{\circ} \mathrm{C}$.

\begin{tabular}{lcc}
\hline Potencial osmótico & \multicolumn{2}{c}{$\mathrm{g} \mathrm{L}^{-1}$ de água destilada } \\
\cline { 2 - 3 }$(\mathrm{MPa})$ & $\mathrm{NaCl}$ & PEG 6000 \\
\hline 0,00 & 0,000 & 0,000 \\
$-0,05$ & 0,655 & 50,080 \\
-0.10 & 1,309 & 78,490 \\
$-0,15$ & 1,964 & 100,701 \\
$-0,20$ & 2,620 & 119,571 \\
$-0,25$ & 3,273 & 136,268 \\
$-0,30$ & 3,928 & 151,402 \\
\hline
\end{tabular}

tratamento. Foram efetuadas contagens aos quatro e oito dias após a semeadura (BRASIL, 1992). Na primeira contagem, usada como teste de vigor, foram retiradas as plântulas normais com comprimento igual ou superior a seis centímetros e os resultados expressos em porcentagem. Foram, também, avaliados o comprimento e a matéria seca, em 25 plântulas de cada repetição, conforme KRZYZANOWSKI et al. (1991).

O delineamento experimental foi um fatorial 2 x 7 (produtos químicos x níveis de potenciais osmóticos), inteiramente casualizado, com quatro repetições. Os dados foram submetidos à análise da variância e a regressão polinomial $(\mathrm{P}<0,05)$. As variáveis de porcentagem foram transformadas previamente para arco seno $(\% / 100)^{1 / 2}$.

\section{RESULTADOS E DISCUSSÃO}

A porcentagem de germinação das sementes manteve-se acima de $90 \%$ até $-0,20 \mathrm{MPa}$ para as duas soluções utilizadas, com porcentagem superior para o $\mathrm{NaCl}$ (Figura 1). A partir de-0,20MPa, houve redução da germinação nas duas soluções $(\mathrm{P}<0,05)$, sendo que em PEG 6000, a redução foi mais drástica, não apresentando plântulas normais em 0,25MPa, enquanto, para o $\mathrm{NaCl}$, a germinação foi satisfatória neste potencial, porém foi considerada insignificante em -0,30MPa. A germinação das sementes de feijão sofreu decréscimo significativo a partir de $50 \mathrm{mmol} \mathrm{L}^{-1}$ de $\mathrm{NaCl}$ e não houve germinação em 200 $\mathrm{mmol} \mathrm{L}^{-1}$ (RIBEIRO et al., 2003). Resultados semelhantes foram obtidos por SANTOS (1996), BRACCINI et al. (1996) e MORAES \& MENEZES (2003) trabalhando com soja. O excesso dos íons $\mathrm{Na}^{+}$ e $\mathrm{Cl}^{-}$tende a causar intumescência protoplasmática, afetando a atividade enzimática e resultando principalmente na produção inadequada de energia por distúrbios na cadeia respiratória (LARCHER, 1986). Com relação ao PEG 6000, os resultados deste trabalho confirmam os obtidos por PERTEL et al. (2003), que observaram reduções significativas na formação de plântulas normais em potenciais osmóticos inferiores a - 0,60MPa. Isso pode estar relacionado com o fato de que soluções de PEG apresentam alta viscosidade, comprometendo a absorção de $\mathrm{O}_{2}$ pelas sementes (YOON et al., 1997).

$\mathrm{O}$ vigor das sementes, na primeira contagem, diminuiu à medida que os potenciais decresceram (Figura 2). Em solução de $\mathrm{NaCl}$, a formação de plântulas normais manteve-se em torno de $90 \%$ até $-0,20 \mathrm{MPa}$, a partir do qual diminuiu drasticamente. Resultados semelhantes também foram obtidos por BRAGA et al. (1999), trabalhando com 


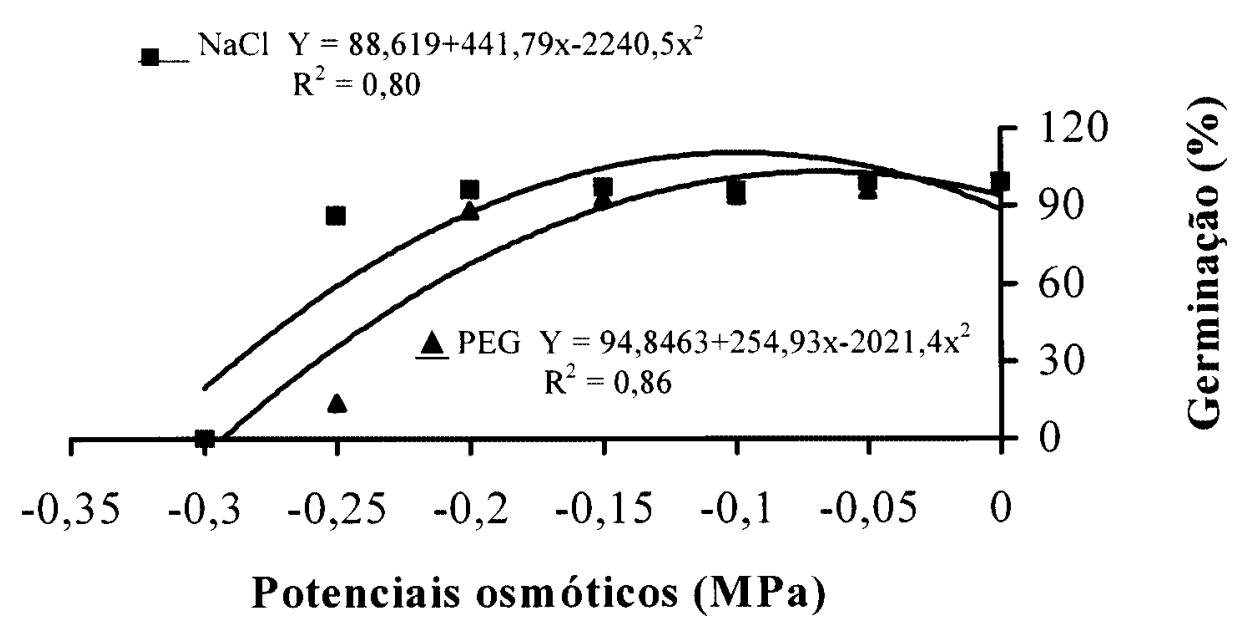

Figura 1 - Germinação de sementes de feijão, cultivar IAPAR 44, submetidas a sete níveis de potencial osmótico em cloreto de sódio ( $\mathrm{NaCl})$ e polietilenoglicol (PEG 6000).

feijão. Para o PEG 6000, a redução do vigor foi mais severa, pois em -0,05MPa, a porcentagem de plântulas normais na primeira contagem reduziu a $60 \%$, assemelhando-se aos resultados obtidos por PERTEL et al. (2003), nos quais, em potenciais inferiores a $-0,40 \mathrm{MPa}$ não houve manifestação do vigor na primeira contagem. Em -0,25 e -0,30MPa, não houve manifestação do vigor para PEG 6000 e $\mathrm{NaCl}$, respectivamente. Esta redução, provavelmente, foi resultante da perda de turgescência protoplasmática, que provoca distúrbios na fisiologia celular e danos nos sistemas de biomembranas, como referiram BRUNI \& LEOPOLD (1992), em seus resultados. Comparando-se os resultados das figuras 1 e 2, observa-se que o vigor das sementes foi mais afetado do que a germinação.

A matéria seca das plântulas decresceu com a redução do potencial osmótico (Figura 3), embora para o $\mathrm{NaCl}$, observou-se um pequeno aumento desta em -0,05 e-0,10MPa, diminuindo nos potenciais mais negativos $(\mathrm{P}<0,05)$. Esses dados confirmam os resultados de PERTEL et al (2003), em que plântulas

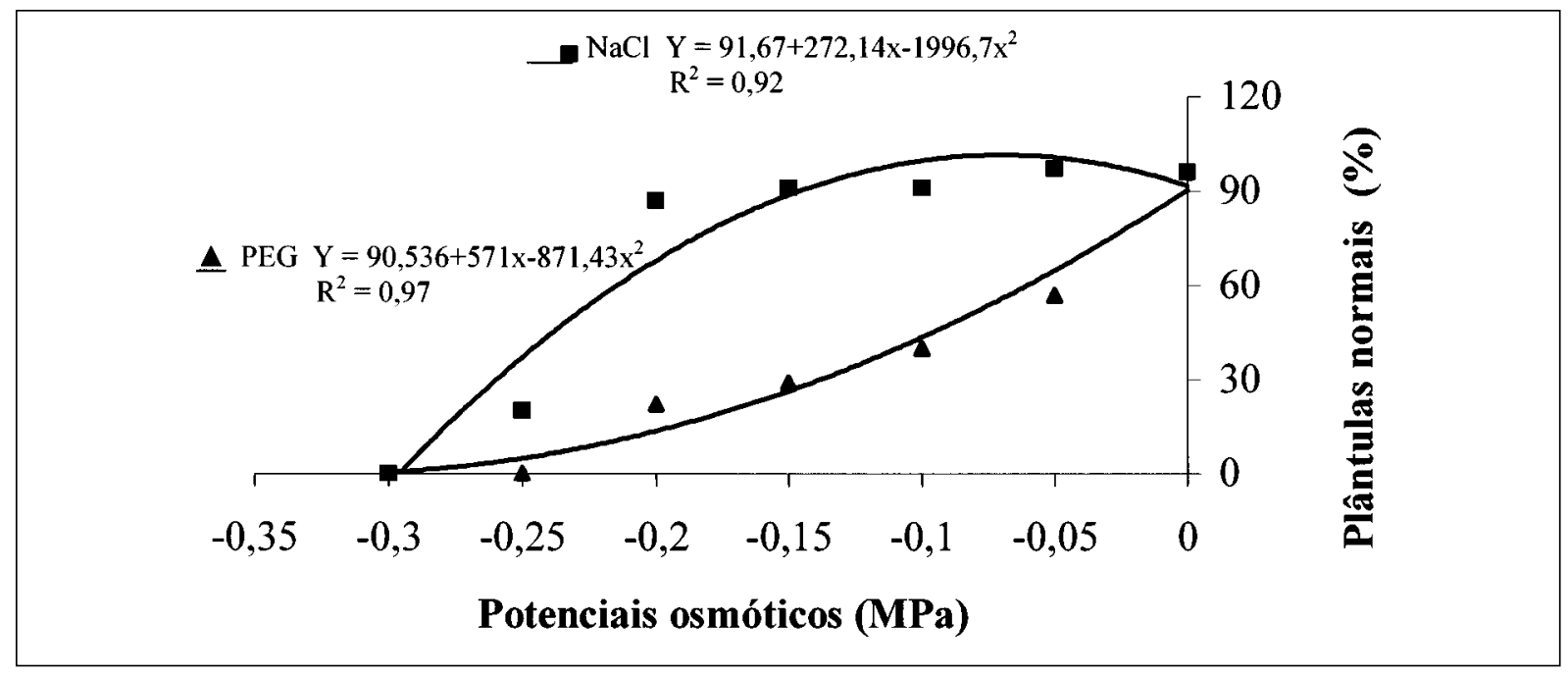

Figura 2 - Primeira contagem do teste de germinação de sementes de feijão, cultivar IAPAR 44, submetidas a sete níveis de potencial osmótico em cloreto de sódio ( $\mathrm{NaCl}$ ) e polietilenoglicol (PEG 6000).

Ciência Rural, v.35, n.4, jul-ago, 2005. 


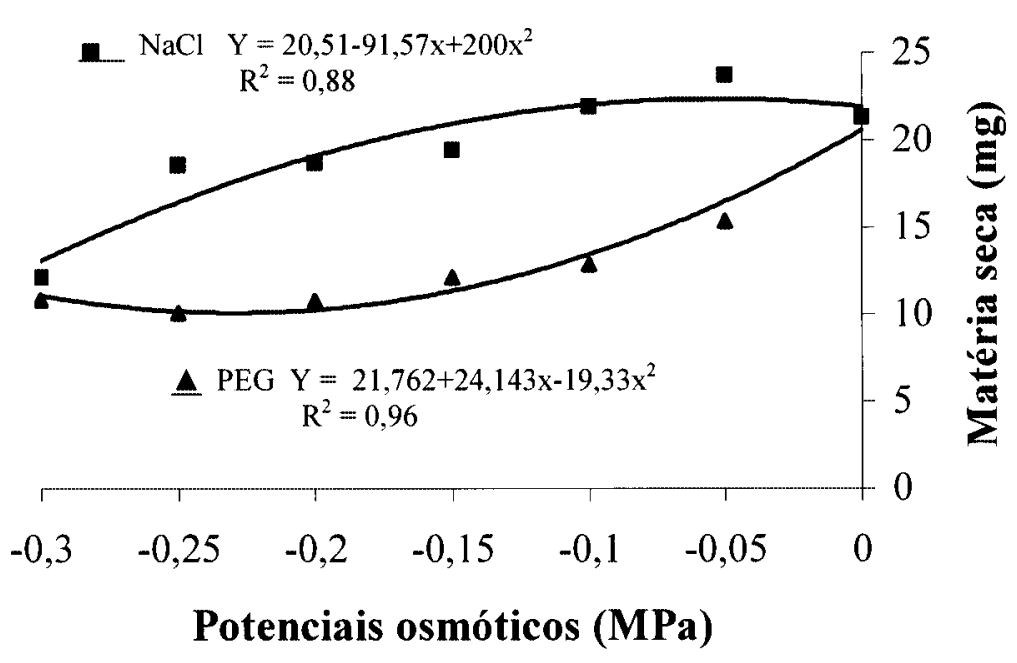

Figura 3 - Matéria seca de plântulas de feijão, cultivar IAPAR 44, oriundas das sementes submetidas a sete níveis de potencial osmótico em cloreto de sódio ( $\mathrm{NaCl}$ ) e polietilenoglicol (PEG 6000).

de feijão tiveram maior matéria seca nas concentrações de 10 e $50 \mathrm{mmol} \mathrm{L}^{-1}$, havendo redução em concentrações mais elevadas. Em soluções de PEG 6000, observouse que o menor valor se deu em -0,30MPa para as duas soluções utilizadas, conforme já obtido por BRACCINI et al. (1996 e 1998) e MORAES \& MENEZES (2003). A redução da matéria seca de plântulas em função da restrição hídrica se dá devido à menor velocidade dos processos fisiológicos e bioquímicos ou pela dificuldade de hidrólise e mobilização das reservas da semente (BEWLEY \& BLACK, 1994).

O comprimento das plântulas foi afetado negativamente pelos tratamentos (Figura 4), de modo semelhante ao ocorrido com a matéria seca. O PEG 6000 apresentou efeito mais drástico, enquanto o $\mathrm{NaCl}$ provocou efeito negativo a partir de-0,05MPa. Esses resultados corroboram aqueles obtidos por REIS et al. (2003) e MORAES \& MENEZES (2003), que trabalharam com sementes de feijão e soja, respectivamente, sendo que, em ambos os casos, os menores potenciais osmóticos reduziram o comprimento das plântulas. Essa redução no comprimento de plântulas se deve a mudanças na turgescência celular em função da diminuição da síntese de proteínas em condições de déficit hídrico (DELL’AQUILLA, 1992). O primeiro efeito mensurável do estresse hídrico é uma diminuição no crescimento causada pela redução da expansão

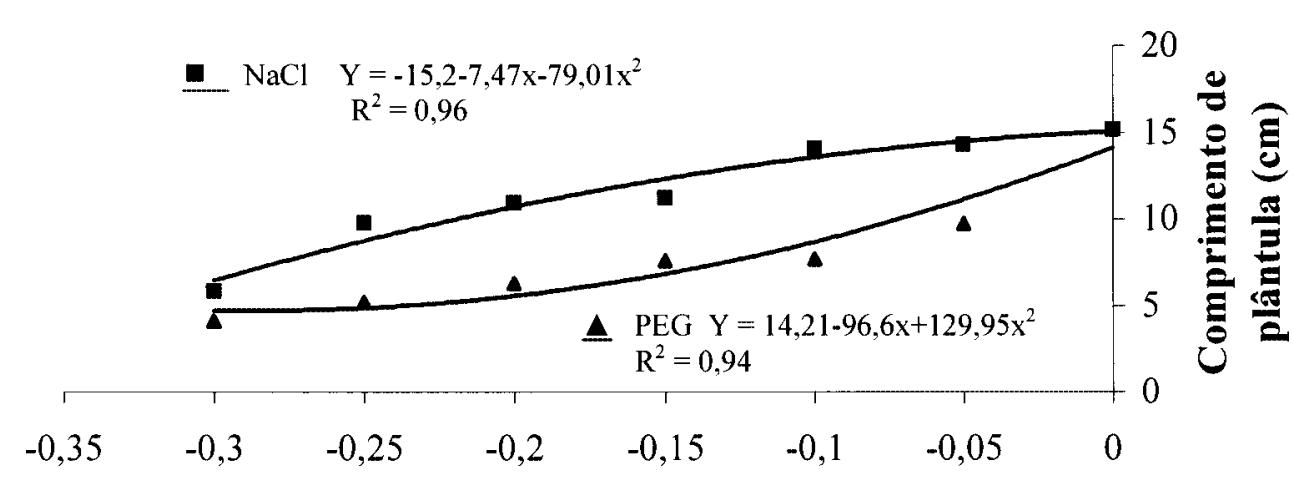

Potenciais osmóticos (MPa)

Figura 4 - Comprimento de plântulas de feijão, cultivar IAPAR 44, oriundas das sementes submetidas a sete níveis de potencial osmótico em cloreto de sódio ( $\mathrm{NaCl}$ ) e polietilenoglicol (PEG 6000).

Ciência Rural, v.35, n.4, jul-ago, 2005. 
celular que necessita de potencial de turgor adequado (TAIZ \& ZEIGER, 2004).

\section{CONCLUSÕES}

O decréscimo nos potenciais osmóticos a partir de-0,20 MPa, induzidos por $\mathrm{NaCl}$ e PEG 6000, reduz o vigor e a germinação das sementes de feijão. $\mathrm{O}$ PEG 6000 produz efeitos mais drásticos na qualidade fisiológica das sementes do que o $\mathrm{NaCl}$.

\section{REFERÊNCIAS}

BEWLEY, J.D.; BLACK, M. Seeds: physiology of development and germination. 2.ed. New York : Plenum, 1994. 445p.

BRACCINI, A.L. et al. Germinação e vigor de sementes de soja sob estresse hídrico induzido por soluções de cloreto de sódio, manitol e polietilenoglicol. Revista Brasileira de Sementes, Brasília, v.18, n.1, p.10-16, 1996.

BRACCINI, A.L. et al. Influência do potencial hídrico induzido por polietilenoglicol na qualidade fisiológica de sementes de soja. Pesquisa Agropecuária Brasileira, Brasília, v.33, n.9, p.1451-1459, 1998.

BRAGA, L.F. et al. Efeito da disponibilidade hídrica na qualidade fisiológica de sementes de feijão. Revista Brasileira de Sementes, Londrina, v.21, n.2, p.95-102, 1999.

BRAY, C.F. Biochemical processes during the osmopriming of seeds. In: KIGEL, J.; GALILI, G. Seed development and germination. New York : Marcel Dekker, 1995. p.767789 .

BRUNI, F.B.; LEOPOLD, A.C. Cytoplasmic glass formation in maize embryos. Seed Science Research, New York, v.2, n.4, p.251-253, 1992.

DELL'AQUILA, A. Water uptake and protein synthesis in germinating wheat embryos under osmotic stress of polyethylene glycol. Annals of Botany, Camberra, v.69, n.2, p.167-171, 1992.

KRZYZANOWKI, F.C. et al. Relato dos testes de vigor disponíveis para as grandes culturas. Informativo ABRATES, Londrina, v.1, n.2, p.15-50, 1991.

LARCHER, W. Ecofisiologia vegetal. São Paulo : EPU, 1986. 319p.

McDONALD, M.B. Jr. et al. Soybean seed imbibition: water absortion by seed parts. Crop Science, Madison. v.28, n.6, p.993-997, 1988.
MIAN, M.A.R.; NAFZIGER, E.D. Seed size and water potential effects on germination and seedling growth of winter wheat. Crop Science, Madison, v.34, n.1, p.169-171, 1994.

MICHEL, B.E.; KAUFMANN, M.R. The osmotic potential of polyethylene glycol 6000. Plant Physiology, Lancaster, v.51, n.6, p.914-916, 1973.

MORAES, G.A.F.; MENEZES, N.L. Desempenho de sementes de soja sob condições diferentes de potencial osmótico. Ciência Rural, Santa Maria, v.33, n.2, p.219226, 2003

PAULA, S.V. et al. Avaliação de plântulas de feijão como critério para seleção de cultivares tolerantes à salinidade. Revista Brasileira de Sementes, Brasília, v.16, n.2, p.220224, 1994.

PAULILO, M.T.S. Efeito do ácido giberélico e 6benziladenina na utilização das reservas da semente de Phaseolus vulgaris L. cv carioca. 1980. 105f. Dissertação (Mestrado em Biologia) - Instituto de Biologia, Universidade Estadual de Campinas.

PERTEL, J. et al. Efeito do estresse hídrico simulado com polietileno glicol na germinação de sementes de feijão, Viçosa, MG, 2003. In: CONGRESSO BRASILEIRO DE SEMENTES, 13., 2003, Gramado, RS. Anais... Londrina : Informativo ABRATES, 2003. V.13. 538p. p.185.

REIS, I.S. et al. Crescimento inicial de plântulas de feijão submetidas a estresse salino. Petrolina, PE, 2003. In: CONGRESSO BRASILEIRO DE SEMENTES, 13., 2003, Gramado, RS. Anais... Londrina : Informativo ABRATES, 2003. V.13. 538p. p.89.

RIBEIRO, L.S. et al. Germinação de sementes de feijão submetidas a estresse salino. Petrolina, PE, 2003. In: CONGRESSO BRASILEIRO DE SEMENTES, 13., 2003, Gramado, RS. Anais... Londrina : Informativo ABRATES, 2003. V.13. p.90.

SANTOS, V.L.M. et al. Utilização do estresse salino na avaliação da qualidade das sementes de genótipos de soja [Glycine Max (L) Merrill]. Revista Brasileira de Sementes, Brasília, v.18, n.1, p.63-72, 1996.

SEONG, R.C. et al. Varietal responses of soybean germination and seedling elongation to temperature and polyethylene glycol solution. Korean Journal of Crop Science, Seoul, v.33, n.1, p.31-37, 1988 .

TAIZ, L.; ZEIGER, E. Fisiologia vegetal. 3.ed. Porto Alegre : ARTMED, 2004. 719p.

YOON, Y. et al. Priming with salt solutions improves germination of pansy seed at high temperatures. HortScience, Alexandria, v.32, n.2, p.248-250, 1997. 